Article

\title{
A Human Skin Model Recapitulates Systemic Sclerosis Dermal Fibrosis and Identifies COL22A1 as a TGF $\beta$ Early Response Gene that Mediates Fibroblast to Myofibroblast Transition
}

\author{
Tomoya Watanabe ${ }^{1}$, DeAnna Baker Frost ${ }^{1}$, Logan Mlakar ${ }^{1}$, Jonathan Heywood ${ }^{1}$, \\ Willian A. da Silveira ${ }^{2}$, Gary Hardiman ${ }^{2,3,4} \mathbb{D}$ and Carol Feghali-Bostwick 1,* \\ 1 Division of Rheumatology and Immunology, Department of Medicine, Medical University of South Carolina, \\ 96 Jonathan Lucas St, MSC 637, Charleston, SC 29425, USA; nabetomo0968@yahoo.co.jp (T.W.); \\ bakerde@musc.edu (D.B.F.); logan.mlakar@gmail.com (L.M.); heywood.jonathan@gmail.com (J.H.) \\ 2 Center for Genomic Medicine, Bioinformatics, Medical University of South Carolina, Charleston, SC 29425, \\ USA; willian.abraham@gmail.com (W.A.d.S.); G.Hardiman@qub.ac.uk (G.H.) \\ 3 Departments of Medicine and Public Health Sciences, Medical University of South Carolina, Charleston, \\ SC 29425, USA \\ 4 School of Biological Sciences \& Institute for Global Food Security, Queens University Belfast, \\ Belfast BT9 5AG, UK \\ * Correspondence: feghalib@musc.edu; Tel.: +1-843-876-2315; Fax: +1-843-792-7121
}

Received: 10 December 2018; Accepted: 14 January 2019; Published: 22 January 2019

\begin{abstract}
Systemic sclerosis (SSc) is a complex multi-system autoimmune disease characterized by immune dysregulation, vasculopathy, and organ fibrosis. Skin fibrosis causes high morbidity and impaired quality of life in affected individuals. Animal models do not fully recapitulate the human disease. Thus, there is a critical need to identify ex vivo models for the dermal fibrosis characteristic of SSc. We identified genes regulated by the pro-fibrotic factor TGF $\beta$ in human skin maintained in organ culture. The molecular signature of human skin overlapped with that which was identified in SSc patient biopsies, suggesting that this model recapitulates the dermal fibrosis characteristic of the human disease. We further characterized the regulation and functional impact of a previously unreported gene in the setting of dermal fibrosis, COL22A1, and show that silencing COL22A1 significantly reduced TGF $\beta$-induced ACTA2 expression. COL22A1 expression was significantly increased in dermal fibroblasts from patients with SSc. In summary, we identified the molecular fingerprint of TGF $\beta$ in human skin and demonstrated that COL22A1 is associated with the pathogenesis of fibrosis in SSc as an early response gene that may have important implications for fibroblast activation. Further, this model will provide a critical tool with direct relevance to human disease to facilitate the assessment of potential therapies for fibrosis.
\end{abstract}

Keywords: fibrosis; systemic sclerosis; COL22A1; fibroblasts; TGF

\section{Introduction}

Systemic sclerosis (SSc) is a multisystem connective tissue disease characterized by immune dysregulation, vasculopathy, and excessive fibrosis of the skin and internal organs due to fibroblast proliferation and production of extracellular matrix [1,2]. It has the highest disease-related mortality and morbidity among the rheumatologic illnesses with impaired quality of life. In fact, fibroproliferative illnesses are responsible for approximately $45 \%$ of deaths in developed countries [3]. The progression of organ fibrosis leads to end-stage organ failure as a result of the loss of normal structure and function. Skin fibrosis causes hardening and tightening of the skin. These features lead to 
limited joint movement or cause joint contractures, diminished mouth opening, and impaired quality of life. However, the mechanisms underlying skin fibrosis remain to be completely elucidated.

Collagen type XXII alpha 1 chain (COL22A1), which is present on human chromosome 8q24.2, exhibits a unique localization at the myotendinous junctions, tendons, heart, articular cartilage, and skin [4]. In the skin, COL22A1 is expressed surrounding the lower third of the anagen hair follicles [4]. Furthermore, COL22A1 is known to act as a cell adhesion ligand for skin epithelial cells and fibroblasts [4]. It belongs to the FACIT (fibril-associated collagens with interrupted triple helix) subset of the collagen superfamily that includes type IX, XII, XIV, XIX, and XXI collagens [5]. These are quantitatively minor collagens that mediate ligand interactions between fibrils and their milieu. They associate with collagen fibers through their C-terminal collagenous domains, and they mediate protein-protein interactions through their $\mathrm{N}$-terminal non-collagenous domains [5]. One of the functions of COL22A1 described in zebrafish is the stabilization of myotendinous junctions and the strengthening of skeletal muscle attachments during contractile activity [6]. Transcript levels of COL22A1 are elevated in the head and neck squamous cell carcinoma (HNSCC) and are proposed as prognostic predictors for HNSCC [7]. In the setting of fibrosis, COL22A1 was identified as a potential causal variant in patients with diffuse cutaneous SSc (dcSSc) through whole-exome sequencing (WES) [8]. COL22A1 was significantly enriched in the extracellular matrix-related pathway. However, the regulation and potential role of COL22A1 in fibrosis and specifically in the pathogenesis of SSc remain unexplored. Since most studies involving the development of fibrosis have examined the effect of pro-fibrotic triggers in vitro in cells such as fibroblasts and in vivo in animal models, in this study, we sought to identify genes regulated by TGF $\beta$ in human skin and found COL22A1 as a top regulated gene. We also investigated the role of COL22A1 in the activation of fibroblasts and the development of fibrosis.

\section{Materials and Methods}

Additional methods can be found in the Supplementary section.

\subsection{Primary Human Skin and Lung Fibroblasts Culture}

Primary fibroblasts were cultured from skin or lung tissues of healthy donors as previously described [9-11]. Lung fibroblasts were obtained under a protocol (\#970946) approved by the Institutional Review Board (IRB) of the University of Pittsburgh, and skin tissues and fibroblasts obtained without identifiers were approved as non-human subject research by the IRB of the Medical University of South Carolina. Fibroblasts were maintained in Dulbecco's Modified Eagle's Medium (DMEM) (Mediatech, Herndon, VA, USA) supplemented with 10\% fetal bovine serum (Sigma-Aldrich, St. Louis, MO, USA), penicillin, streptomycin, and antimycotic agent (Invitrogen, Carlsbad, CA, USA) and used in passages two to seven. Skin fibroblasts were treated with TGF $\beta(5 \mathrm{ng} / \mathrm{mL})(\mathrm{R} \& \mathrm{D}$ Systems, Minneapolis, MN, USA) and harvested 2, 4, 8, 16, 24, $48 \mathrm{~h}$ (for RNA), and $72 \mathrm{~h}$ (for protein) post-treatment. Lung fibroblasts were treated with TGF $\beta(10 \mathrm{ng} / \mathrm{mL})$ and harvested $48 \mathrm{~h}$ (for RNA) and $72 \mathrm{~h}$ (for protein) post-treatment. A549 cells were treated similarly to lung fibroblasts.

\subsection{Small Interfering RNA (siRNA) Transfection}

Primary human skin fibroblasts were seeded at a density of $2 \times 10^{5}$ cells per well in six well plates $24-48 \mathrm{~h}$ prior to transfection with siRNA. ON-TARGETplus COL22A1-specific siRNA and ON-TARGETplus control siRNA were purchased from Dharmacon (Lafayette, CO, USA). Transfection was done using Lipofectamine 2000 (Invitrogen) and $100 \mathrm{nmol}$ siRNA diluted in Opti-MEM I Reduced-Serum Medium (Life Technologies, Carlsbad, CA, USA) following the manufacturer's recommendation. TGF $\beta$ was added to media of cells $24 \mathrm{~h}$ after transfection. Fibroblasts were harvested 24 or $48 \mathrm{~h}$ (for RNA) and $72 \mathrm{~h}$ (for protein) post-treatment. 


\subsection{Ex Vivo Human Skin Culture}

Normal human skin was obtained from residual tissue following plastic surgery. All tissues were obtained according to the guidelines of the Medical University of South Carolina Institutional Review Board without any identifiers. Subcutaneous fat tissue was removed. The skin was cut with a disposable biopsy $3 \mathrm{~mm}$ punch, and the pieces of tissue were cultured in medium containing TGF $\beta(10 \mathrm{ng} / \mathrm{mL})$ or a vehicle control. The culture medium was DMEM supplemented with penicillin, streptomycin, and anti-mycotic agent (Invitrogen). Skin samples were cultured in an air-liquid interface with the epidermal side up. Skin tissues were harvested at 2, 4, 8, 16, 24, and $48 \mathrm{~h}$ (for RNA) or $72 \mathrm{~h}$ (for histological analysis) post-treatment.

\subsection{Quantitative PCR}

Total RNA was extracted from human skin tissues and cultured fibroblasts using the TRIZOL Lysis Reagent (Life Technologies) and RNeasy ${ }^{\circledR}$ kit (Qiagen Inc., Valencia, CA, USA). Reverse transcription was performed with SuperScript IV (Invitrogen). Gene messenger RNA (mRNA) expression levels were evaluated using quantitative PCR by the TaqMan ${ }^{\circledR}$ real-time PCR system (Life Technologies) according to the manufacturer's protocol on a TaqMan ${ }^{\circledR}$ Gene Expression Assays Step One Plus real-time PCR system (Life Technologies). Premixed PCR primers and TaqMan probes for human COL1A1, COL22A1, $C T G F, F N, A C T A 2$, and GAPDH were obtained from Life Technologies. Gene expression levels were normalized to $G A P D H$ and compared with the $2^{-\triangle \Delta C t}$ method.

\subsection{Western Blot Analysis}

Western blot analysis of fibroblast lysates and supernatants was done as previously described [11]. The following antibodies were used: Anti-COL22A1 (Novus, Littleton, CO, USA), fibronectin, collagen 1A1, CTGF, GAPDH (Santa Cruz, Dallas, TX, USA), ACTA2 (Sigma-Aldrich), and horseradish peroxidase-labeled secondary antibody (Santa Cruz). Signals were detected by chemiluminescence (ProteinSimple, San Jose, CA, USA).

\subsection{RNA Expression Profiling}

Total RNA was extracted from human skin tissues using TRIZOL Lysis Reagent (Life Technologies) and the RNeasy ${ }^{\circledR}$ kit (Qiagen Inc.) and was processed by the MUSC Genomics core for $1 \times 50$ cycles, using single-end RNA sequencing on an Illumina HiSeq2500. The RNA integrity was verified on an Agilent 2200 TapeStation (AgilentTechnologies, Palo Alto, CA, USA). A total of 100 ng of total RNA was used to prepare RNA-Seq libraries using the TruSeq RNA Sample Prep kit following the protocol described by the manufacturer (Illumina, San Diego, CA, USA). Sequencing was performed on an Illumina HiSeq2500. Samples were demultiplexed using CASAVA (Illumina).

\subsection{Bioinformatics and Statistical Analysis}

For the differential gene expression analysis, we utilized the OnRamp's advanced Genomics Analysis Engine as previously described [12]. We used human genome build GRCh37/hg19 as the reference and the following programs and versions: Fastqc version 0.11.5, cutadapt version 1.11, Star aligner version 2.5.2b, HTseq version 0.7.0, DESEq2 Version 1.18.1. A gene was considered differentially expressed (DE) if it was below the 0.4 adjusted p-value threshold cut-off as determined by the Benjamini-Hochberg false discovery rate (FDR) correction [13]. A systems-level analysis of the biological pathways affected by the DE genes was carried out using the iPathway Guide tool from Advaita ${ }^{\circledR}$ Bioinformatics [14]. The dataset was deposited into the GEO repository under the accession number GSE109350. 


\subsection{Statistical Analysis}

All continuous variables were expressed as the mean \pm standard deviation. All statistical analyses were done using IBM SPSS statistics 22 (IBM Corporation, NY, USA). Statistical comparisons were performed using the unpaired Student's $t$-test. Comparison of 3 or more groups was done using ANOVA with a post-hoc Tukey's test to evaluate statistical significance.

\section{Results}

\subsection{TGF $\beta$ Increases COL22A1 Expression Ex Vivo and In Vitro}

To identify new genes that may be involved in the development of dermal fibrosis mediated by TGF $\beta$ in human skin, we performed high-throughput RNA sequencing (RNA-seq) using ex vivo human skin samples treated with TGF $\beta$ or a vehicle control for $48 \mathrm{~h}$. Gene expression profiling identified several novel transcripts in human skin tissues that were significantly upregulated by TGF $\beta$ including COL22A1, Prostate Transmembrane Protein, Androgen Induced 1 (PMEPA1), Dermatopontin $(D P T)$, and others (Table 1). A complete list of all differentially-expressed genes regulated by TGF $\beta$ (530 using an FDR cutoff of 0.1, and 1051 when the FDR stringency was set at 0.4) is shown in Supplementary Table S1. A heatmap of the top 100 most significantly differentially expressed mRNAs as determined by DESeq2 (FDR $<0.1)$ is shown in Supplementary Figure S1. Pathway analysis suggested that the top impacted pathway was the ECM-receptor interaction, followed by Proteoglycans in cancer, Cell cycle, and Cytokine-cytokine receptor interaction (Supplementary Table S2).

Table 1. The significant differentially expressed (DE) messenger RNA (mRNAs) as determined by DESeq2 (false discovery rate, FDR < 0.1) using ex vivo human skin samples treated with TGF $\beta$ or a vehicle control for $48 \mathrm{~h}$. The top 100 most significant DE mRNAs ranked by FDR (padj) are presented.

\begin{tabular}{|c|c|c|c|c|}
\hline Symbol & GeneID & Description & Padj & $\begin{array}{l}\text { Fold } \\
\text { Change }\end{array}$ \\
\hline COL22A1 & 169044 & collagen, type XXII, alpha 1 & $6.40 \times 10^{-36}$ & 9.19 \\
\hline PMEPA1 & 56937 & $\begin{array}{l}\text { prostate transmembrane protein, } \\
\text { androgen induced } 1\end{array}$ & $6.36 \times 10^{-33}$ & 3.51 \\
\hline$D P T$ & 1805 & dermatopontin & $2.89 \times 10^{-29}$ & 4.69 \\
\hline LTBP2 & 4053 & $\begin{array}{c}\text { latent transforming growth factor beta } \\
\text { binding protein } 2\end{array}$ & $6.31 \times 10^{-26}$ & 3.18 \\
\hline COL1A1 & 1277 & collagen, type I, alpha 1 & $2.49 \times 10^{-23}$ & 3.11 \\
\hline FN1 & 2335 & fibronectin 1 & $2.78 \times 10^{-20}$ & 3.39 \\
\hline MMP10 & 4319 & matrix metallopeptidase 10 & $6.47 \times 10^{-13}$ & 2.76 \\
\hline COL3A1 & 1281 & collagen, type III, alpha 1 & $5.68 \times 10^{-12}$ & 2.34 \\
\hline DHRS2 & 10202 & $\begin{array}{c}\text { dehydrogenase/reductase (SDR family) } \\
\text { member } 2\end{array}$ & $6.16 \times 10^{-12}$ & 4.55 \\
\hline COL5A2 & 1290 & collagen, type $\mathrm{V}$, alpha 2 & $8.53 \times 10^{-12}$ & 2.36 \\
\hline ITGB6 & 3694 & integrin, beta 6 & $1.66 \times 10^{-11}$ & 2.94 \\
\hline ADAMTS15 & 170689 & $\begin{array}{l}\text { ADAM metallopeptidase with } \\
\text { thrombospondin type } 1 \text { motif, } 15\end{array}$ & $1.77 \times 10^{-11}$ & 3.55 \\
\hline LRRC15 & 131578 & leucine rich repeat containing 15 & $1.77 \times 10^{-11}$ & 4.17 \\
\hline TGFBI & 7045 & $\begin{array}{l}\text { transforming growth factor, beta-induced, } \\
688 \mathrm{kDa}\end{array}$ & $6.21 \times 10^{-11}$ & 3.12 \\
\hline MKI67 & 4288 & marker of proliferation Ki-67 & $7.29 \times 10^{-11}$ & -2.56 \\
\hline COL1A2 & 1278 & collagen, type I, alpha 2 & $8.85 \times 10^{-11}$ & 2.11 \\
\hline ADAM12 & 8038 & ADAM metallopeptidase domain 12 & $3.00 \times 10^{-10}$ & 2.71 \\
\hline GLS & 2744 & glutaminase & $3.08 \times 10^{-10}$ & 2.08 \\
\hline MIAT & 440823 & $\begin{array}{l}\text { myocardial infarction associated } \\
\text { transcript (non-protein coding) }\end{array}$ & $3.36 \times 10^{-10}$ & 3.23 \\
\hline
\end{tabular}


Table 1. Cont

\begin{tabular}{|c|c|c|c|c|}
\hline Symbol & GeneID & Description & Padj & $\begin{array}{c}\text { Fold } \\
\text { Change }\end{array}$ \\
\hline C4orf 26 & 152816 & chromosome 4 open reading frame 26 & $3.59 \times 10^{-10}$ & 4.07 \\
\hline WNT5B & 81029 & $\begin{array}{l}\text { wingless-type MMTV integration site } \\
\text { family, member 5B }\end{array}$ & $1.01 \times 10^{-9}$ & 3.58 \\
\hline KRT77 & 374454 & keratin 77 , type II & $3.56 \times 10^{-9}$ & 2.19 \\
\hline CXCL14 & 9547 & chemokine (C-X-C motif) ligand 14 & $7.49 \times 10^{-9}$ & 2.61 \\
\hline TPST1 & 8460 & tyrosylprotein sulfotransferase 1 & $8.75 \times 10^{-9}$ & 2.58 \\
\hline COL15A1 & 1306 & collagen, type $\mathrm{XV}$, alpha 1 & $1.03 \times 10^{-8}$ & 2.75 \\
\hline SNAI1 & 6615 & snail family zinc finger 1 & $1.04 \times 10^{-8}$ & 2.65 \\
\hline NKD1 & 85407 & naked cuticle homolog 1 (Drosophila) & $2.62 \times 10^{-8}$ & 3.41 \\
\hline LDLRAD4 & 753 & $\begin{array}{c}\text { low density lipoprotein receptor class A } \\
\text { domain containing } 4\end{array}$ & $1.43 \times 10^{-7}$ & 3.30 \\
\hline NPR3 & 4883 & natriuretic peptide receptor 3 & $1.46 \times 10^{-7}$ & 2.96 \\
\hline DHRS9 & 10170 & $\begin{array}{c}\text { dehydrogenase/reductase (SDR family) } \\
\text { member } 9\end{array}$ & $1.64 \times 10^{-7}$ & -2.44 \\
\hline COL5A1 & 1289 & collagen, type $\mathrm{V}$, alpha 1 & $2.11 \times 10^{-7}$ & 2.11 \\
\hline ESM1 & 11082 & endothelial cell-specific molecule 1 & $2.11 \times 10^{-7}$ & 2.83 \\
\hline DIRAS1 & 148252 & DIRAS family, GTP-binding RAS-like 1 & $2.17 \times 10^{-7}$ & 2.51 \\
\hline DLGAP5 & 9787 & $\begin{array}{c}\text { discs, large (Drosophila) } \\
\text { homolog-associated protein } 5\end{array}$ & $3.77 \times 10^{-7}$ & -2.66 \\
\hline RRM2 & 6241 & ribonucleotide reductase M2 & $7.85 \times 10^{-7}$ & -2.46 \\
\hline TPM1 & 7168 & tropomyosin 1 (alpha) & $7.85 \times 10^{-7}$ & 2.55 \\
\hline VCAN & 1462 & versican & $8.57 \times 10^{-7}$ & 2.42 \\
\hline CENPF & 1063 & centromere protein $\mathrm{F}, 350 / 400 \mathrm{kDa}$ & $9.28 \times 10^{-7}$ & -2.54 \\
\hline CEP55 & 55165 & centrosomal protein $55 \mathrm{kDa}$ & $1.84 \times 10^{-6}$ & -2.49 \\
\hline SOX9 & 6662 & SRY (sex determining region Y)-box 9 & $1.84 \times 10^{-6}$ & 1.93 \\
\hline HECW2 & 57520 & $\begin{array}{c}\text { HECT, } \mathrm{C} 2 \text { and WW domain containing E3 } \\
\text { ubiquitin protein ligase } 2\end{array}$ & $2.00 \times 10^{-6}$ & 2.61 \\
\hline PRSS23 & 11098 & protease, serine, 23 & $2.00 \times 10^{-6}$ & 2.44 \\
\hline SPRR2D & 6703 & small proline-rich protein $2 \mathrm{D}$ & $2.42 \times 10^{-6}$ & -1.78 \\
\hline GADD $45 B$ & 4616 & $\begin{array}{l}\text { growth arrest and } \\
\text { DNA-damage-inducible, beta }\end{array}$ & $2.70 \times 10^{-6}$ & 1.98 \\
\hline KIF4A & 24137 & kinesin family member $4 \mathrm{~A}$ & $2.84 \times 10^{-6}$ & -2.55 \\
\hline CACNA1C & 775 & $\begin{array}{l}\text { calcium channel, voltage-dependent, } \mathrm{L} \\
\text { type, alpha } 1 C \text { subunit }\end{array}$ & $2.87 \times 10^{-6}$ & 2.69 \\
\hline$L A R P 6$ & 55323 & $\begin{array}{c}\text { La ribonucleoprotein domain family, } \\
\text { member } 6\end{array}$ & $3.68 \times 10^{-6}$ & 2.23 \\
\hline MMP13 & 4322 & matrix metallopeptidase 13 & $3.83 \times 10^{-6}$ & 3.02 \\
\hline FGFBP2 & 83888 & fibroblast growth factor binding protein 2 & $5.18 \times 10^{-6}$ & 2.93 \\
\hline TOP2A & 7153 & topoisomerase (DNA) II alpha 170kDa & $6.21 \times 10^{-6}$ & -2.37 \\
\hline DNAH17 & 8632 & dynein, axonemal, heavy chain 17 & $7.27 \times 10^{-6}$ & 1.98 \\
\hline IL11 & 3589 & interleukin 11 & $8.58 \times 10^{-6}$ & 2.68 \\
\hline EREG & 2069 & epiregulin & $9.06 \times 10^{-6}$ & -2.16 \\
\hline PHLDB1 & 23187 & $\begin{array}{l}\text { pleckstrin homology-like domain, family } \\
\text { B, member } 1\end{array}$ & $9.42 \times 10^{-6}$ & 1.95 \\
\hline IQGAP3 & 128239 & $\begin{array}{l}\text { IQ motif containing GTPase activating } \\
\text { protein } 3\end{array}$ & $9.76 \times 10^{-6}$ & -2.42 \\
\hline$A 2 M L 1$ & 144568 & alpha-2-macroglobulin-like 1 & $9.83 \times 10^{-6}$ & -1.84 \\
\hline NDC80 & 10403 & NDC80 kinetochore complex component & $1.02 \times 10^{-5}$ & -2.57 \\
\hline TROAP & 10024 & trophinin associated protein & $1.20 \times 10^{-5}$ & -2.45 \\
\hline$C D C A 8$ & 55143 & cell division cycle associated 8 & $1.40 \times 10^{-5}$ & -2.24 \\
\hline TRIP13 & 9319 & thyroid hormone receptor interactor 13 & $1.89 \times 10^{-5}$ & -2.33 \\
\hline GPRC5A & 9052 & $\begin{array}{c}\text { G protein-coupled receptor, class } C, \\
\text { group } 5 \text {, member } A\end{array}$ & $2.19 \times 10^{-5}$ & 2.37 \\
\hline ARL15 & 54622 & ADP-ribosylation factor-like 15 & $2.51 \times 10^{-5}$ & 2.32 \\
\hline CDC20 & 991 & cell division cycle 20 & $2.68 \times 10^{-5}$ & -2.48 \\
\hline
\end{tabular}


Table 1. Cont.

\begin{tabular}{|c|c|c|c|c|}
\hline Symbol & GeneID & Description & Padj & $\begin{array}{l}\text { Fold } \\
\text { Change }\end{array}$ \\
\hline BIRC5 & 332 & baculoviral IAP repeat containing 5 & $2.69 \times 10^{-5}$ & -2.34 \\
\hline LYPD1 & 116372 & LY6/PLAUR domain containing 1 & $2.81 \times 10^{-5}$ & 2.77 \\
\hline$D C L K 3$ & 85443 & doublecortin-like kinase 3 & $2.91 \times 10^{-5}$ & 2.78 \\
\hline$A U R K B$ & 9212 & aurora kinase B & $2.91 \times 10^{-5}$ & -2.28 \\
\hline$M Y B L 2$ & 4605 & $\begin{array}{l}\text { v-myb avian myeloblastosis viral } \\
\text { oncogene homolog-like } 2\end{array}$ & $3.49 \times 10^{-5}$ & -2.09 \\
\hline MFAP2 & 4237 & microfibrillar-associated protein 2 & $3.53 \times 10^{-5}$ & 1.88 \\
\hline WNT2 & 7472 & $\begin{array}{l}\text { wingless-type MMTV integration site } \\
\text { family member } 2\end{array}$ & $3.53 \times 10^{-5}$ & 2.76 \\
\hline$S 100 A 7 A$ & 338324 & S100 calcium binding protein A7A & $3.77 \times 10^{-5}$ & -2.12 \\
\hline NREP & 9315 & neuronal regeneration related protein & $3.86 \times 10^{-5}$ & 1.92 \\
\hline PKMYT1 & 9088 & $\begin{array}{l}\text { protein kinase, membrane associated } \\
\text { tyrosine/threonine } 1\end{array}$ & $4.74 \times 10^{-5}$ & -2.07 \\
\hline HMCN2 & 256158 & hemicentin 2 & $5.10 \times 10^{-5}$ & 2.69 \\
\hline$C D C 45$ & 8318 & cell division cycle 45 & $5.23 \times 10^{-5}$ & -2.05 \\
\hline TICRR & 90381 & $\begin{array}{l}\text { TOPBP1-interacting checkpoint and } \\
\text { replication regulator }\end{array}$ & $6.00 \times 10^{-5}$ & -2.40 \\
\hline SETBP1 & 26040 & SET binding protein 1 & $6.31 \times 10^{-5}$ & 1.87 \\
\hline TPX2 & 22974 & TPX2, microtubule-associated & $6.31 \times 10^{-5}$ & -2.25 \\
\hline KIFC1 & 3833 & kinesin family member C1 & $6.49 \times 10^{-5}$ & -2.27 \\
\hline CDCA5 & 113130 & cell division cycle associated 5 & $6.62 \times 10^{-5}$ & -2.12 \\
\hline PRICKLE1 & 144165 & prickle homolog 1 (Drosophila) & $7.37 \times 10^{-5}$ & 2.23 \\
\hline$L B H$ & 81606 & limb bud and heart development & $8.71 \times 10^{-5}$ & 2.31 \\
\hline CCL28 & 56477 & chemokine (C-C motif) ligand 28 & $8.81 \times 10^{-5}$ & 2.48 \\
\hline FAM150B & 285016 & $\begin{array}{l}\text { family with sequence similarity } 150, \\
\text { member B }\end{array}$ & $8.81 \times 10^{-5}$ & 2.65 \\
\hline SKA3 & 221150 & $\begin{array}{l}\text { spindle and kinetochore associated } \\
\text { complex subunit } 3\end{array}$ & $9.14 \times 10^{-5}$ & -2.41 \\
\hline PRC1 & 9055 & protein regulator of cytokinesis 1 & $9.24 \times 10^{-5}$ & -2.12 \\
\hline TACC3 & 10460 & $\begin{array}{l}\text { transforming, acidic coiled-coil } \\
\text { containing protein } 3\end{array}$ & $9.34 \times 10^{-5}$ & -1.96 \\
\hline KIF18B & 146909 & kinesin family member 18B & $1.05 \times 10^{-4}$ & -2.25 \\
\hline CD83 & 9308 & CD83 molecule & $1.09 \times 10^{-4}$ & 2.07 \\
\hline TMEM $86 A$ & 144110 & transmembrane protein 86A & $1.09 \times 10^{-4}$ & -1.88 \\
\hline RUNX1 & 861 & runt-related transcription factor 1 & $1.18 \times 10^{-4}$ & 1.99 \\
\hline ATP12A & 479 & $\begin{array}{l}\text { ATPase, } \mathrm{H}+/ \mathrm{K}+\text { transporting, nongastric, } \\
\text { alpha polypeptide }\end{array}$ & $1.25 \times 10^{-4}$ & -2.26 \\
\hline$M A P 1 B$ & 4131 & microtubule-associated protein $1 \mathrm{~B}$ & $1.25 \times 10^{-4}$ & 1.71 \\
\hline$B G N$ & 633 & biglycan & $1.30 \times 10^{-4}$ & 2.43 \\
\hline PNMAL1 & 55228 & paraneoplastic Ma antigen family-like 1 & $1.31 \times 10^{-4}$ & 2.25 \\
\hline TK1 & 7083 & thymidine kinase 1 , soluble & $1.42 \times 10^{-4}$ & -2.08 \\
\hline$B M P 6$ & 654 & bone morphogenetic protein 6 & $1.46 \times 10^{-4}$ & 2.19 \\
\hline HPSE & 10855 & heparanase & $1.61 \times 10^{-4}$ & -1.77 \\
\hline SEMA7A & 8482 & $\begin{array}{l}\text { semaphorin 7A, GPI membrane anchor } \\
\text { (John Milton Hagen blood group) }\end{array}$ & $1.73 \times 10^{-4}$ & 1.78 \\
\hline CCL8 & 6355 & chemokine (C-C motif) ligand 8 & $1.82 \times 10^{-4}$ & -2.56 \\
\hline
\end{tabular}

Among the differentially-regulated genes, COL22A1 was the most highly regulated (fold change $\left.(\mathrm{FC})=9.19, \mathrm{FDR}=6.40 \times 10^{-36}\right)$. Therefore, we focused on characterizing the levels and potential function of COL22A1 in skin fibrosis. To confirm the results of the RNA-seq, we first examined the mRNA and protein levels of COL22A1 in ex vivo human skin samples using quantitative reverse transcription PCR (qRT-PCR) and immunofluorescence, respectively. TGF $\beta$ significantly increased expression levels of COL22A1 in human skin from different donors (Figure 1a). Immunofluorescence analysis also revealed COL22A1 protein in the dermal layer of human skin treated with TGF $\beta$, 
whereas no COL22A1 was detected in human skin treated with the vehicle control (Figure 1b). Since fibroblasts are effector cells in dermal fibrosis [15], and having observed COL22A1 in the dermal layer of the skin, we next asked whether COL22A1 expression is increased by TGF $\beta$ in skin fibroblasts. TGF $\beta$ significantly increased the expression of COL22A1 in skin fibroblasts from healthy donors. This was confirmed at the protein level using Western blot analysis (Figure 1c). We also examined the ability of TGF $\beta$ to increase COL22A1 expression in other cell types. Interestingly, mRNA and protein levels of COL22A1 were significantly increased by TGF $\beta$ in normal human lung fibroblasts (Figure 1d) and A549 cells (Figure 1e), which are adenocarcinomic human alveolar basal epithelial cells. Thus, TGF $\beta$ can induce COL22A1 expression both in the skin- and lung-derived cells.

a

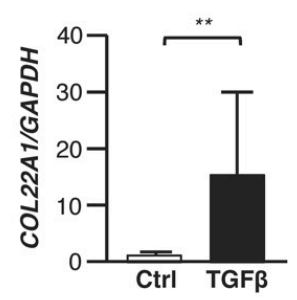

C

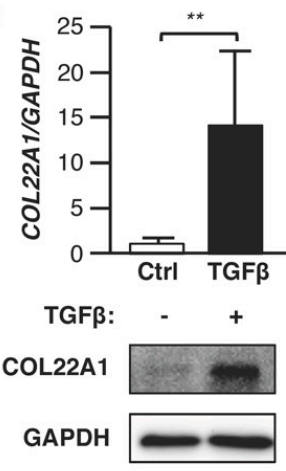

d
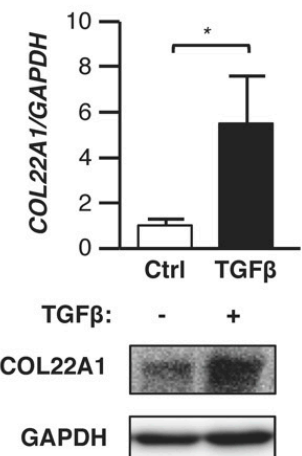

b

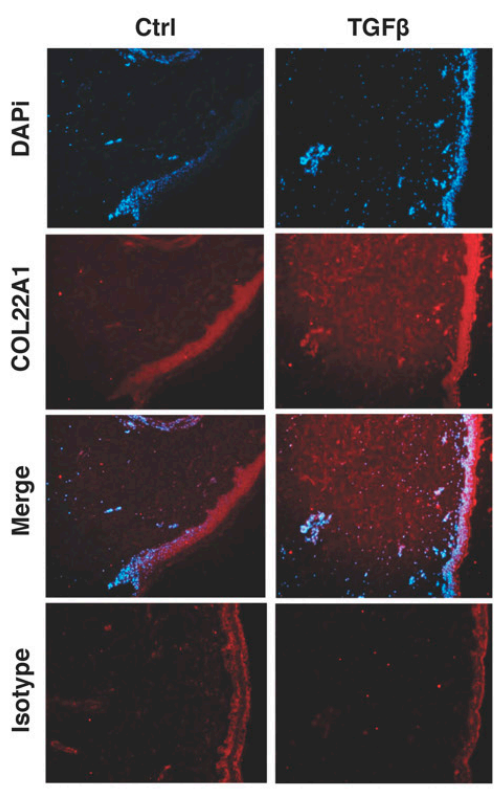

e

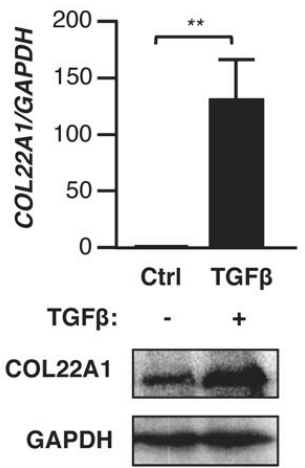

Figure 1. TGF $\beta$ increases expression levels of COL22A1 ex vivo and in vitro. $(\mathbf{a}, \mathbf{b})$ Human skin samples were treated with TGF $\beta(10 \mathrm{ng} / \mathrm{mL}$ ) for 48 and $72 \mathrm{~h}$. (a) Expression levels of COL22A1 were measured in human skin $(\mathrm{N}=5)$; ${ }^{* *} p<0.01$. (b) Localization of COL22A1 in ex vivo normal skin. COL22A1 was detected using immunofluorescence in a vehicle control or TGF $\beta$-treated skin tissue. DAPI was used to detect nuclei (original magnification $\times 40$ ); scale bars $=100 \mu \mathrm{m}$. (c) Human normal skin fibroblasts were treated with TGF $\beta$ ( $5 \mathrm{ng} / \mathrm{mL}$ ) for 24 or $72 \mathrm{~h}$. Expression levels of COL22A1 mRNA were measured in human normal skin fibroblasts $(\mathrm{N}=9) ;{ }^{* *} p<0.01$. Protein levels of COL22A1 in the skin fibroblasts of three healthy donors were analyzed by immunoblotting of the lysates; GAPDH is shown as a loading control. (d) Human normal lung fibroblasts were treated with TGF $\beta$ (10 ng/mL) for 48 or $72 \mathrm{~h}$. Expression levels of COL22A1 mRNA were measured in human normal lung fibroblasts treated with 
a vehicle control or TGF $\beta(\mathrm{N}=3) ;{ }^{*} p<0.05$. The protein levels of COL22A1 in lung fibroblasts were analyzed by immunoblotting of the lysates. (e) A549 cells were treated with TGF $\beta(5 \mathrm{ng} / \mathrm{mL})$ for 24 or $72 \mathrm{~h}$. Expression levels of COL22A1 mRNA were measured in A549 cells treated with a vehicle control or TGF $\beta(\mathrm{N}=3) ;{ }^{* *} p<0.01$. Protein levels of COL22A1 in the A549 cells were analyzed by immunoblotting of the lysates.

To further investigate the mechanisms involved in COL22A1 expression, we examined whether other fibrosis-promoting growth factors, such as interleukin (IL-6), bleomycin (BLM), and Platelet-Derived Growth Factor (PDGF)-BB, induce COL22A1 expression in dermal fibroblasts after $24 \mathrm{~h}$. IL-6 and BLM showed modest increases in COL22A1 expression in skin fibroblasts, while PDGF-BB had no effect (Supplementary Figure S2A,B).

\subsection{COL22A1 Is a TGF $\beta$ Early Response Gene}

To evaluate time-dependent changes induced by TGF $\beta$, we measured the mRNA levels of COL22A1 in ex vivo human skin samples. Human skin samples treated with TGF $\beta$ were harvested at $2,4,8,16$, and $24 \mathrm{~h}$. TGF $\beta$ showed a time-dependent increase in COL22A1 expression. mRNA levels of COL22A1 were significantly upregulated starting at $8 \mathrm{~h}$ after stimulation with TGF $\beta$ (Figure 2a). We next compared time-dependent changes in normal skin fibroblasts. Similar to ex vivo human skin, significantly increased levels of COL22A1 mRNA in skin fibroblasts were noted $4 \mathrm{~h}$ after TGF $\beta$ treatment (Figure 2b). This upregulation in skin fibroblasts was slightly earlier than that observed in ex vivo human skin. We further analyzed the expression of known fibrosis-related genes at the same time points. qRT-PCR analysis revealed that the expression levels of collagen type I alpha chain (COL1A1), fibronectin $(F N)$, and alpha 2 smooth muscle actin (ACTA2) were significantly increased at later time points (after 16 or $24 \mathrm{~h}$ of TGF $\beta$ treatment) compared with those of COL22A1 (Figure 2c-e). In contrast, significant increases in connective tissue growth factor (CTGF) expression were observed as early as $2 \mathrm{~h}$ after TGF $\beta$ treatment (Figure 2f). Thus, TGF $\beta$ induces COL22A1 expression earlier than other extracellular matrix genes and ACTA2, while the early response of the COL22A1 expression is comparable to that seen with the early response gene CTGF.

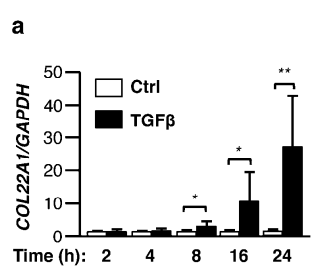

b
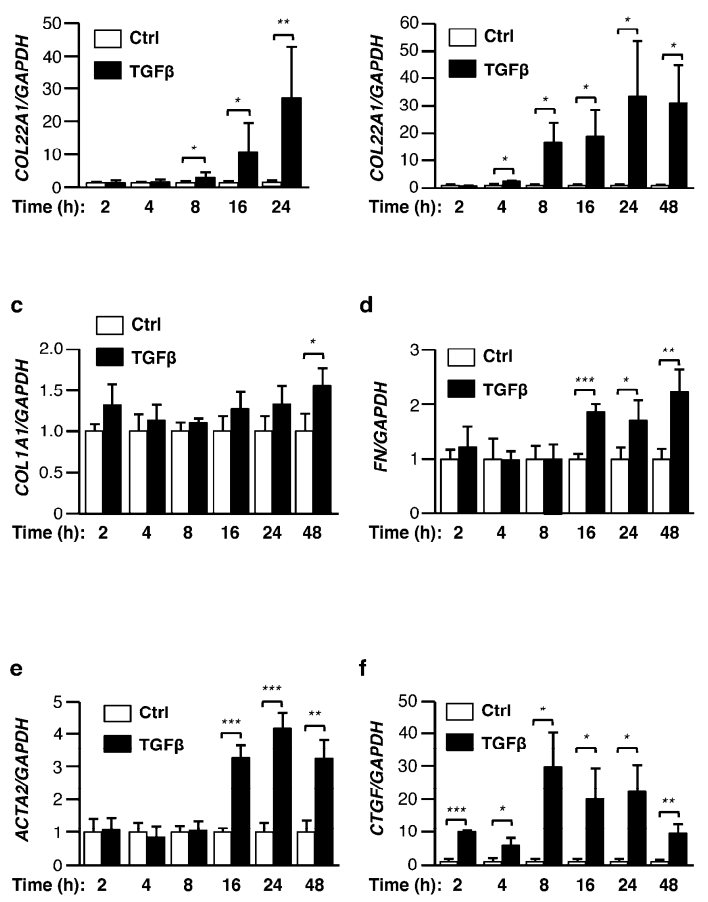

Figure 2. COL22A1 is an early response gene ex vivo and in vitro. Human skin and fibroblasts treated with TGF $\beta$ ( 5 or $10 \mathrm{ng} / \mathrm{mL}$ ) were harvested at the indicated time points. 
(a) The expression levels of COL22A1 mRNA were measured in normal human skin in organ culture $(\mathrm{N}=5) ;{ }^{*} p<0.05$; ${ }^{* *} p<0.01$. (b) Expression levels of COL22A1 mRNA were measured in primary human skin fibroblasts $(\mathrm{N}=3)$ : ${ }^{*} p<0.05$. (c) COL1A1 mRNA levels; ${ }^{*} p<0.05$. (d) FN mRNA levels; ${ }^{*} p<0.05$; ${ }^{* *} p<0.01$; ${ }^{* * *} p<0.001$. (e) ACTA2 mRNA levels: ${ }^{* *} p<0.01$; ${ }^{* * *} p<0.001$. (f) CTGF mRNA levels: ${ }^{*} p<0.05 ;{ }^{* *} p<0.01 ;{ }^{* *} p<0.001$.

\subsection{TGF $\beta$-Induced COL22A1 Expression Depends on ALK5 and MEK Activation}

To investigate which TGF $\beta$ signaling cascades are involved in the induction of COL22A1 expression, normal skin fibroblasts were cultured with TGF $\beta$ in combination with specific inhibitors of ALK5 (SB431542), MEK (U0126), PI3K (LY294002), and JNK signaling. TGF $\beta$ induction of COL22A1 expression was abrogated by ALK5 and MEK inhibition (Figure 3a). JNK inhibition partly blocked the TGF $\beta$-induced expression of COL22A1. On the other hand, TGF $\beta$-induced COL22A1 expression was not affected by PI3K inhibition (Figure 3a). Similar effects were observed at the protein level (Figure 3b). These results suggest that the induction of COL22A1 expression by TGF $\beta$ is mediated by ALK5 and MEK signaling.

a

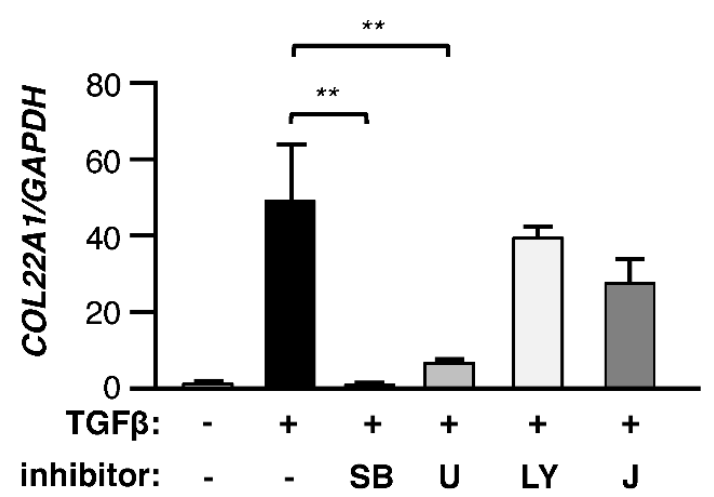

b

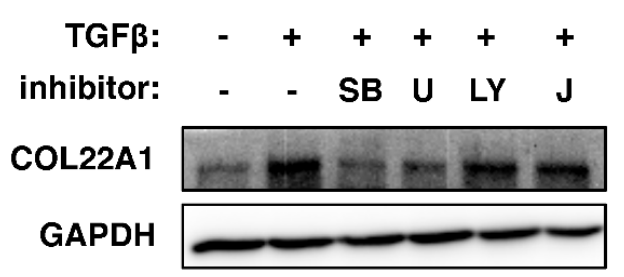

Figure 3. TGF $\beta$-induced COL22A1 expression is inhibited by MEK and ALK5 inhibitors. Skin fibroblasts were incubated with $10 \mu \mathrm{mol} / \mathrm{L}$ SB431542 (SB), U0126 (U), LY294002 (LY), JNK inhibitor II (J), or DMSO as a vehicle control for $1 \mathrm{~h}$ before the addition of TGF $\beta$ ( $5 \mathrm{ng} / \mathrm{mL})$. Skin fibroblasts were stimulated with TGF $\beta$ for 24 and $72 \mathrm{~h}$. (a) Expression levels of COL22A1 were measured using qPCR $(\mathrm{N}=4)$; ${ }^{* *} p<0.01$. (b) Representative data from immunoblotting of lysates are shown. GAPDH was used as a loading control.

\subsection{Silencing COL22A1 Reduces TGF $\beta$-Induced ACTA2 Expression}

Since COL22A1 expression was induced by TGF $\beta$ earlier than other genes, we examined the potential role of COL22A1 knockdown on TGF $\beta$ regulation of other fibrosis-related genes. Normal skin fibroblasts were transfected with COL22A1 siRNA and then stimulated with TGF $\beta$. An average of $60 \%$ silencing of COL22A1 was achieved in unstimulated fibroblasts compared to control siRNA (Figure 4a). COL22A1 mRNA levels also decreased significantly in TGF $\beta$-stimulated fibroblasts. Similarly, protein 
levels of COL22A1 were decreased by silencing COL22A1 (Figure 4b). We further investigated whether other fibrosis related genes were affected by COL22A1 knockdown. Interestingly, TGF $\beta$-induced ACTA2 expression was significantly decreased following COL22A1 silencing (Figure 4c). This effect was also observed at the protein level (Figure 4d). COL22A1 silencing reduced TGF $\beta$ induction of COL1A1 and to a lesser degree that of $F N$, but the differences did not reach statistical significance. The protein levels of COL1A1 were also reduced. On the other hand, mRNA and protein levels of CTGF were not affected by COL22A1 knockdown. These results indicate that COL22A1 may mediate TGF $\beta$ induction of ACTA2, and possibly COL1A1.

a

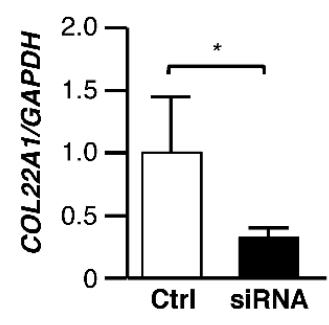

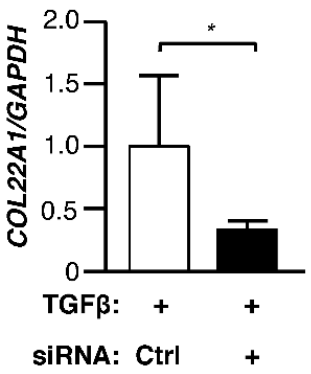

b

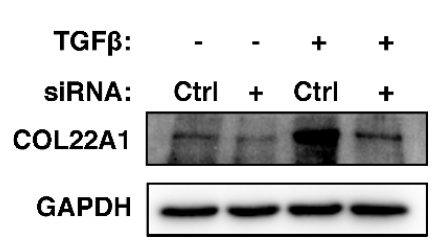

C
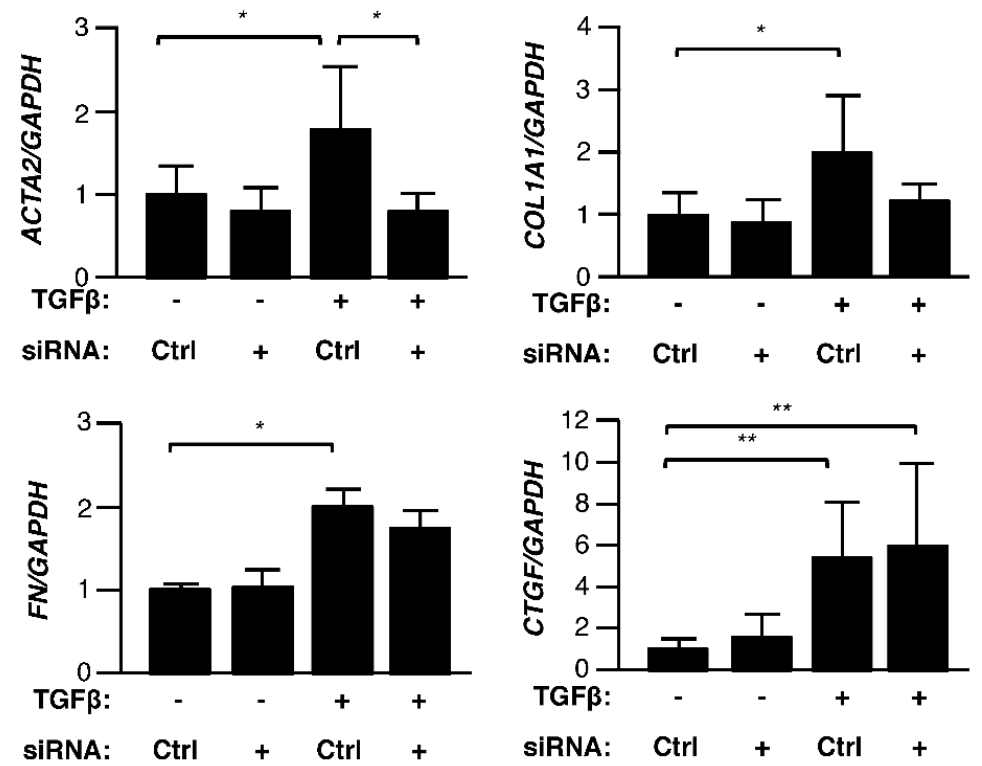

d

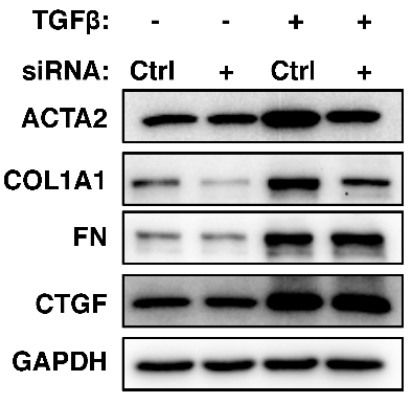

Figure 4. Silencing COL22A1 reduces expression levels of ACTA2. Normal skin fibroblasts were transfected with control or COL22A1 siRNA and treated with TGF $\beta(5 \mathrm{ng} / \mathrm{mL})$ for 48 and $72 \mathrm{~h}(\mathrm{~N}=4)$. (a) Expression levels of COL22A1 mRNA were measured; * $p<0.05$. (b) Protein levels of COL22A1 were analyzed by immunoblotting of lysates. GAPDH is shown as a loading control. (c) Expression levels of fibrosis-related genes were measured; ${ }^{*} p<0.05 ;{ }^{* *} p<0.01$. (d) Representative protein levels in lysates from fibroblasts transfected with control or COL22A1 siRNA. 
To determine whether COL22A1 silencing alters the contractile capacity of dermal fibroblasts, we examined the effect of silencing COL22A1 expression on dermal fibroblast-mediated collagen gel contraction. Our data show that COL22A1 silencing in the absence of TGF $\beta$ modestly decreased the baseline gel contraction capacity of fibroblasts. However, COL22A1 silencing did not significantly alter TGF $\beta$-mediated collagen gel contraction of fibroblasts, even though it resulted in a pronounced reduction of TGF $\beta$-induced ACTA2 expression (Supplementary Figure S3).

\subsection{COL22A1 Expression Is Elevated in SSc Skin Fibroblasts}

Since SSc is a disease characterized by dermal fibrosis, we compared mRNA and protein levels of COL22A1 in skin fibroblasts from control donors and patients with the diffuse cutaneous form of SSc. COL22A1 expression was significantly increased in fibroblasts from lesional SSc skin (SSc-affected skin fibroblasts; SSc-Aff) and non-lesional SSc skin (SSc-unaffected skin fibroblasts; SSc-Un) compared to normal skin fibroblasts (Figure 5a). In contrast, no significant differences were found between affected and unaffected SSc fibroblasts. Protein levels of COL22A1 in SSc-affected fibroblasts were also higher than those in normal skin fibroblasts (Figure 5b). These findings suggest that COL22A1 levels are elevated in fibroblasts from patients with SSc-associated dermal fibrosis, and due to its role in mediating TGF $\beta$ regulation of ACTA2 and myofibroblast differentiation, COL22A1 may be involved in the pathogenesis of SSc dermal fibrosis.

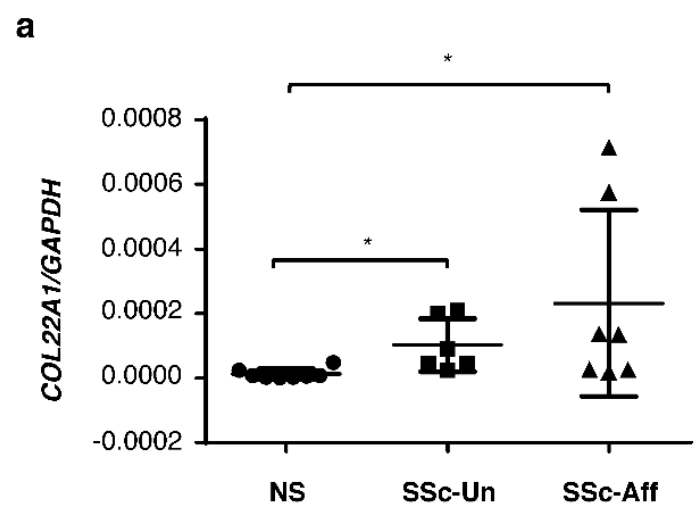

b

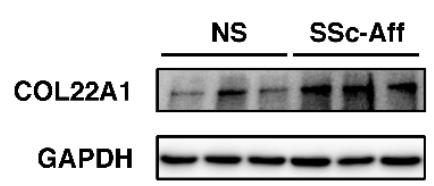

Figure 5. Increased expression levels of COL22A1 in SSc skin fibroblasts. Skin fibroblasts from healthy donors and patients with SSc were cultured in serum-free DMEM for 48 and $72 \mathrm{~h}$. (a) Expression levels of COL22A1 mRNA were measured in the indicated group (HC; $\mathrm{N}=8$, SSc-Un; $\mathrm{N}=6$, SSc-Aff; $\mathrm{N}=7$ ); ${ }^{*} p<0.05$. (b) Protein levels of COL22A1 were detected in normal skin fibroblasts and SSc skin fibroblasts using immunoblotting. GAPDH is shown as a loading control. NS = normal skin fibroblasts; SSc-Un = SSc-unaffected skin fibroblasts; SSc-Aff = SSc-affected skin fibroblasts.

3.6. Genes Identified as Differentially Expressed in TGF $\beta$-Treated Human Skin Overlap with SSc Patient Skin Signatures

To assess the similarity in the response of human skin in organ culture to a well-accepted signature of human SSc skin, we compared the gene signature identified in our model to that identified in primary fibroblasts stimulated with TGF $\beta$ as reported by Sargent et al. [16], and to the SSc skin signature identified by Milano et al. [17]. Sargent et al. carried out in vitro exposure of adult dermal fibroblasts from healthy and SSc patients and derived a gene signature for TGF $\beta$ responsiveness 
comprised of 674 unique genes. In their study, they reanalyzed a prior data set from Milano et al., derived from 75 arrays from patients with different disease severity. Although their 674 unique gene signatures distinguished the dSSc and healthy patients (53 arrays), this signature was noisy when applied to the extended data set with different disease progression represented. This signature was therefore refined to a smaller subset that better differentiated the dSSc and normal groups. We noted that these array 474 probes described by Sargent et al. corresponded to 371 genes. We looked for overlaps with all 1051 transcripts differentially expressed (FDR $\leq 0.4)$ in our study. To minimize technical noise associated with microarray experimentation and experimental differences between laboratories, we required that the direction of the fold change was the same between both studies, i.e., if a gene was reported as upregulated by Sargent et al., it also needed to be in this study for further consideration as a biomarker. This stringent filtering resulted in a 48 gene overlaps between our study and that of Sargent at al., and a heatmap of these transcripts which clearly distinguishes the control and TGF $\beta$ treated groups is presented in Figure 6. These findings suggest that our human skin ex vivo model is a suitable model for the dermal fibrosis characteristic of SSc.

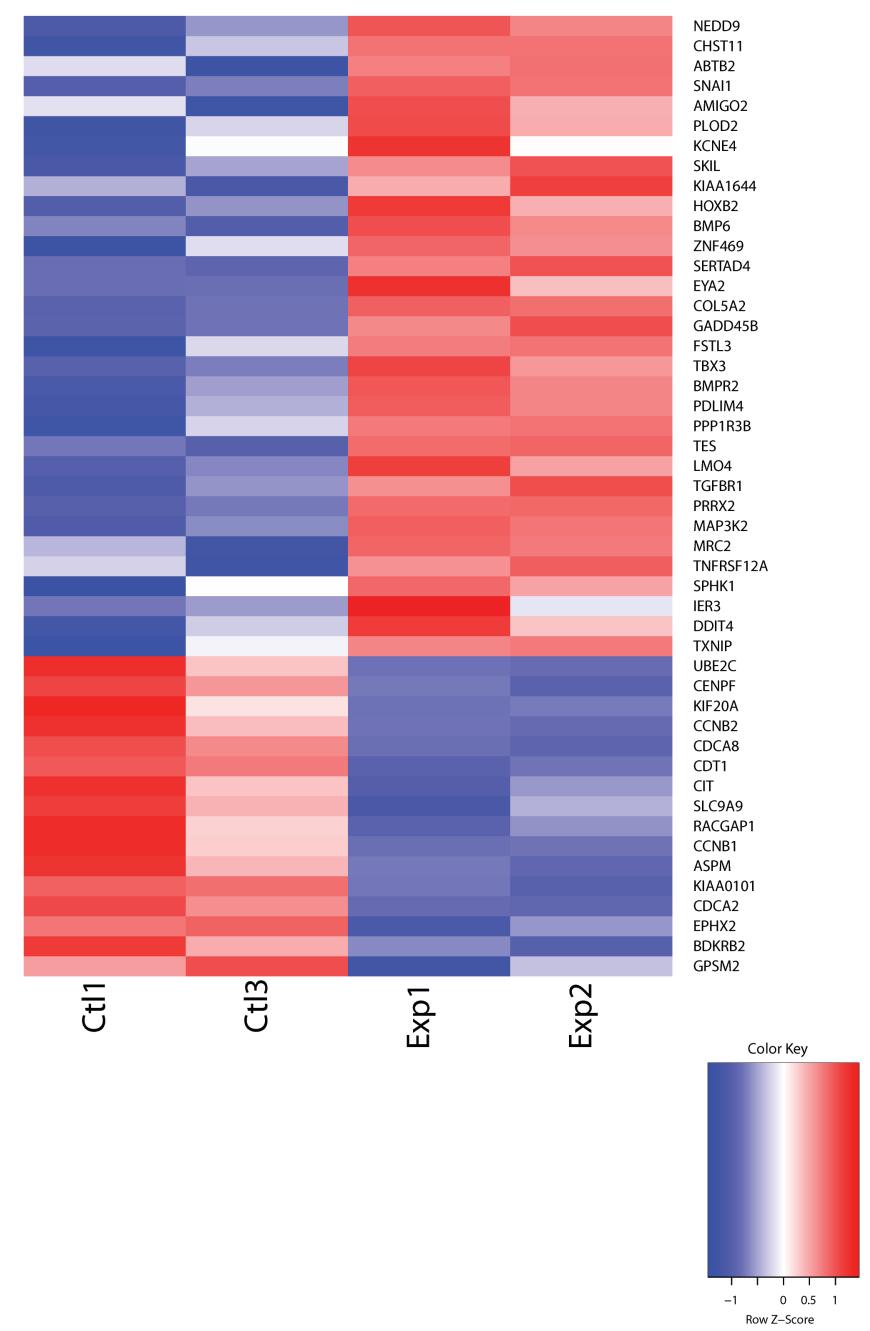

Figure 6. The heatmap of the 48-gene overlap between our study (significant DE mRNAs as determined by DESeq2 (FDR < 0.1) ) and the 371 gene signature that differentiates the dSSc and the normal state described by Sargent et al. The red and blue boxes indicate relative over- and under-expression with respect to a reference which is calculated as the mid-point between the control and TGF $\beta$ treated groups. 


\section{Discussion}

Research on fibrosis has relied on the use of in vitro assays and in vivo mouse and rat models. However, many of the agents tested in animals have not been efficacious in humans in clinical trials. Using human skin as an ex vivo organ model of fibrosis has great potential to examine mechanisms underlying fibrosis because this model more closely mimics the skin fibrosis characteristic of human SSc than the current in vitro and in vivo models. In fact, we have previously shown that factors such as IGFBP-5, IGFBP-3, and TGF $\beta$ can induce fibrosis in human skin maintained in organ culture [18-20]. We now show that our ex vivo human skin model is a suitable model for the dermal fibrosis characteristic of SSc. The signature obtained from the human skin stimulated with TGF $\beta$ and maintained in organ culture overlaps with the signature identified in two key studies using human dcSSc skin biopsies and human fibroblasts stimulated with TGF $\beta[16,17]$. The 48-gene signature in the overlap between our model and these studies demonstrates the utility and relevance of our model for research focusing on dermal fibrosis in SSc.

RNA-seq using ex vivo human skin samples is a powerful tool for identifying new genes that may contribute to disease pathogenesis and their functional analysis. Using RNAseq, we identified the transcripts regulated by TGF $\beta$ in human skin, with COL22A1 showing the greatest differential expression. Our findings reveal that in normal skin-derived fibroblasts, TGF $\beta$ significantly increased COL22A1 expression. Furthermore, fibroblasts from the skin of dcSSc patients expressed high levels of COL22A1 compared with normal skin fibroblasts. These findings suggest that upregulated COL22A1 expression may be associated with the pathogenesis of fibrosis in patients with SSc and/or may be a biomarker for human dermal fibrosis. To the best of our knowledge, this study is the first to investigate the levels (both mRNA and protein) and the role of COL22A1 in the setting of fibrosis.

Our analysis revealed that COL22A1 is a TGF $\beta$-inducible immediate early gene in skin fibroblasts while other fibrosis-promoting growth factors had a very modest effect on COL22A1 expression. TGF $\beta$ has been shown to induce several downstream genes such as CTGF, EGR-1, and Endothelin-1 (ET-1) at an early stage compared with other fibrosis-associated genes [21-23]. These factors play an important role in the deposition of extracellular matrix components including fibronectin and collagen by fibroblasts in the development and maintenance of fibrosis. In fact, CTGF is an inducible matricellular protein involved in tissue remodeling, and its expression is increased during wound repair. CTGF mediates some of the effects of TGF $\beta$, and CTGF transgenic mice were shown to have multi-organ fibrosis [24]. The fact that COL22A1 expression is induced early while that of other ECM genes and ACTA2 are increased in a delayed manner raises the possibility that COL22A1 may mediate the TGF $\beta$ induction of pro-fibrotic factors. Indeed, siRNA experiments showed that silencing COL22A1 reduced $A C T A 2, C O L 1 A 1$, and $F N$ expression and late-response genes downstream of TGF $\beta$, but not CTGF expression, which is induced earlier than COL22A1. These results lead us to speculate that COL22A1 acts upstream of ACTA2, COL1A1, and FN and regulates their expression through the TGF $\beta$ signaling pathway.

In addition, COL22A1 showed a higher magnitude of response to TGF $\beta$ than other TGF $\beta$ regulated genes we examined. Other fibrosis-associated genes such as COL1A1, FN, and ACTA2, which are late response targets of TGF $\beta$, showed increased expression of $2-5$-fold following TGF $\beta$ stimulation, whereas the early response genes such as COL22A1, CTGF (Figure 3f), and EGR-1 [25] showed more than a 30-fold induction in expression in skin fibroblasts. This greater response may reflect the acute phase of the response to TGF $\beta$, while the late response genes are more characteristic of the chronic response to TGF $\beta$ and other triggers of fibrosis. Although COL22A1 silencing decreased TGF $\beta$-mediated ACTA2 expression and $\alpha$ SMA levels, it did not affect the contraction of fibroblasts in the collagen gel. $\alpha \mathrm{SMA}$ is a component of stress fibers in fibroblasts; however, its inhibition is not sufficient to prevent contraction. In fact, $\alpha \mathrm{SMA}$ knockout mice show a delay in skin wound healing, suggesting that $\alpha \mathrm{SMA}$ contributes to wound healing but is not necessary [26]. Additionally, $\alpha$ SMA null mice retained the ability to form myofibroblasts and contractile forces in response to TGF $\beta$ [27]. This may be in part due to the fact that additional proteins can compensate for the absence 
of $\alpha$ SMA. For instance, in fibroblasts and myofibroblasts isolated from $\alpha$ SMA knockout mice, other actin forms were found at higher levels post-TGF $\beta$ simulation [27]. Additionally, non-muscle myosins colocalize with actin and participate in contraction during wound healing [28]. Thus, fibroblasts have compensatory proteins that may reduce the functional impact of the $\alpha \mathrm{SMA}$ decrease on cell contraction.

Regulation of COL22A1 expression by fibrosis-promoting growth factors also appears to provide some insights into mechanisms regulating COL22A1 expression by TGF $\beta$. PDGF-BB did not increase COL22A1 expression, while IL-6 and BLM modestly increased its levels. Our experiments using TGF $\beta$ signaling cascade inhibitors identified pathways regulating COL22A1 expression. PDGF is known to result in the activation of JAK/STAT, PI3K, phospholipase C- $\gamma$ (PLC- $\gamma$ ) or MAPK signaling pathways [29]. The binding of IL-6 to its receptor leads to the activation of JAK/STAT and Ras-mediated signaling [30]. In addition, IL-6 also activates PI3K [30,31]. Similar to these factors, BLM does not activate ALK5 or MEK signaling pathways. However, we showed that the activation of PI3K was not required to induce COL22A1 expression at the mRNA and protein levels. In this regard, ALK5 and MEK signaling pathways seem to play a key role in mediating the TGF $\beta$ regulation of COL22A1 expression, explaining, at least in part, why TGF $\beta$ was more potent for inducing COL22A1 expression.

COL22A1 is expressed in tissue junctions, tendons, heart, articular cartilage, and skin [4]. However, no studies to date have assessed COL22A1 expression in lung tissue-derived cells. We demonstrate that the expression levels of COL22A1 were increased by TGF $\beta$ in adenocarcinomic human alveolar basal epithelial cells and lung fibroblasts. These results suggest that that COL22A1 may be associated with the development of lung fibrosis as well as skin fibrosis via increased expression in resident fibroblasts contributing to their activation and transition to myofibroblasts. Furthermore, TGF $\beta$-induced COL22A1 expression may induce epithelial mesenchymal transition (EMT) in human alveolar epithelial cells. EMT is a biologic process that involves an epithelial cell acquiring a mesenchymal cell phenotype, which includes enhanced migratory capacity, resistance to apoptosis, and increased production of ECM components [32]. In fact, TGF $\beta$ stimulation promotes alveolar epithelial cell transition to a myofibroblast-like phenotype in lung tissues [33]. EMT is also found to be associated with fibrosis occurring in different organs including the kidney, liver, lung, and intestine. Therefore, the high induction of COL22A1 by TGF $\beta$ in A549 cells and lung fibroblasts, in conjunction with the reduction of ACTA2 and COL1A1 expression by COL22A1 silencing, leads us to speculate that COL22A1 may be associated with the transition of fibroblasts and epithelial cells to myofibroblasts, effector cells that play an important role in extracellular matrix production and fibrosis. In fact, in the skin, COL22A1 is expressed surrounding the lower third of anagen hair follicles and acts as a cell adhesion ligand for skin epithelial cells and fibroblasts [4]. It has been reported that ACTA2 is expressed in human hair follicles and that hair follicle-derived smooth muscle cells express ACTA2 [34]. It is thus conceivable that hair follicle cells can be another source of the myofibroblasts characteristic of fibrotic skin. Furthermore, since hair follicles are involved in perifollicular fibrosis, and our findings suggest skin localization of COL22A1, it is likely that COL22A1 may also play an important role in perifollicular fibrosis and may promote cell adhesion and migration of hair follicle-derived smooth muscle cells.

In conclusion, our findings suggest that the increased expression of COL22A1 is associated with the pathogenesis of fibrosis in SSc and that the regulation of COL22A1 expression may have important implications for skin fibrosis as well as lung fibrosis. These results add to our understanding of the pathogenic mechanism of fibrosis by generating novel insights into genes regulated under pro-fibrotic conditions in human skin, providing direct relevance to human dermal fibrosis.

Supplementary Materials: The following are available online at http:/ / www.mdpi.com/2073-4425/10/2/75/s1, Figure S1: Heatmap of significantly differentially expressed mRNAs as determined by DESeq2 (FDR < 0.1) using ex vivo human skin samples treated with TGF $\beta(10 \mathrm{ng} / \mathrm{mL})$ or a vehicle control for $48 \mathrm{~h}$, Figure S2: Human normal skin fibroblasts were treated with IL-6 (20 ng/mL), PDGF-BB (40 ng/mL), or BLM (10 mU/mL) for 24 or 72 h, Figure S3: Decreased expression of ACTA2 in TGF $\beta$-treated fibroblasts deficient in COL22A1 does not alter TGF $\beta$-induced collagen gel contraction, Table S1: Significantly DE mRNAs as determined by DESeq2 using ex vivo human skin samples treated with TGF $\beta(10 \mathrm{ng} / \mathrm{mL})$ or a vehicle control for $48 \mathrm{~h}$, Table S2: The most significantly impacted biological pathways due to TGF $\beta$ treatment, ranked by adjusted $p$ value from most 
significant to least significant, Supplemental method 1: Immunofluorescence, Supplemental method 2: Fibroblast treatment, Supplemental method 3: Collagen Gel Contraction Assay.

Author Contributions: T.W., C.F.B., G.H. contributed to experimental design; T.W., C.F.B., G.H., W.A.d.S., D.B.F., L.M., and J.H. contributed to data acquisition; T.W., C.F.B., G.H., W.A.d.S. and D.B.F. contributed to data analysis and interpretation; all authors contributed to manuscript drafting and editing.

Funding: This work was supported in part by the SmartState and Kitty Trask Holt Endowment and grant K24AR060297 from NIH/NIAMS (C.F.B.), the E. Carwile LeRoy, MD, Endowed Research Fellowship (T.W.), KL2TR001452 (D.B.F.), UL1TR001450, and the Genomics Shared Resource, Hollings Cancer Center and the Center for Genomic Medicine at the Medical University of South Carolina (G.H.). GH acknowledges funding from SC EPSCoR and G.H. and C.F.B. acknowledge start-up funding from the College of Medicine at the Medical University of South Carolina.

Conflicts of Interest: The authors declare no conflict of interest.

\section{References}

1. Almeida, I.; Faria, R.; Vita, P.; Vasconcelos, C. Systemic sclerosis refractory disease: From the skin to the heart. Autoimmun Rev. 2011, 10, 693-701. [CrossRef] [PubMed]

2. Steen, V.D.; Medsger, T.A., Jr. Epidemiology and natural history of systemic sclerosis. Rheum. Dis. Clin. North Am. 1990, 16, 1-10. [PubMed]

3. Wynn, T.A. Common and unique mechanisms regulate fibrosis in various fibroproliferative diseases. J. Clin. Investig. 2007, 117, 524-529. [CrossRef] [PubMed]

4. Koch, M.; Schulze, J.; Hansen, U.; Ashwodt, T.; Keene, D.R.; Brunken, W.J.; Burgeson, R.E.; Bruckner, P.; Bruckner-Tuderman, L. A novel marker of tissue junctions, collagen XXII. J. Biol. Chem. 2004, 279, 22514-22521. [CrossRef]

5. Ricard-Blum, S.; Ruggiero, F. The collagen superfamily: From the extracellular matrix to the cell membrane. Pathol. Biol. 2005, 53, 430-442. [CrossRef] [PubMed]

6. Charvet, B.; Guiraud, A.; Malbouyres, M.; Zwolanek, D.; Guillon, E.; Bretaud, S.; Monnot, C.; Schulze, J.; Bader, H.L.; Allard, B.; et al. Knockdown of COL22A1 gene in zebrafish induces a muscular dystrophy by disruption of the myotendinous junction. Development 2013, 140, 4602-4613. [CrossRef] [PubMed]

7. Misawa, K.; Kanazawa, T.; Imai, A.; Endo, S.; Mochizuki, D.; Fukushima, H.; Misawa, Y.; Mineta, H. Prognostic value of type XXII and XXIV collagen mRNA expression in head and neck cancer patients. Mol. Clin. Oncol. 2014, 2, 285-291. [CrossRef] [PubMed]

8. Mak, A.C.; Tang, P.L.; Cleveland, C.; Smith, M.H.; Kari Connolly, M.; Katsumoto, T.R.; Wolters, P.J.; Kwok, P.Y.; Criswell, L.A. Brief Report: Whole-Exome Sequencing for Identification of Potential Causal Variants for Diffuse Cutaneous Systemic Sclerosis. Arthritis Rheumatol. 2016, 68, 2257-2262. [CrossRef]

9. Feghali, C.A.; Wright, T.M. Identification of multiple, differentially expressed messenger RNAs in dermal fibroblasts from patients with systemic sclerosis. Arthritis Rheum. 1999, 42, 1451-1457. [CrossRef]

10. Hsu, E.; Shi, H.; Jordan, R.M.; Lyons-Weiler, J.; Pilewski, J.M.; Feghali-Bostwick, C.A. Lung tissues in patients with systemic sclerosis have gene expression patterns unique to pulmonary fibrosis and pulmonary hypertension. Arthritis Rheum. 2011, 63, 783-794. [CrossRef]

11. Pilewski, J.M.; Liu, L.; Henry, A.C.; Knauer, A.V.; Feghali-Bostwick, C.A. Insulin-like growth factor binding proteins 3 and 5 are overexpressed in idiopathic pulmonary fibrosis and contribute to extracellular matrix deposition. Am. J. Pathol. 2005, 166, 399-407. [CrossRef]

12. Davis-Turak, J.; Courtney, S.M.; Hazard, E.S.; Glen, W.B.; da Silveira, W.A.; Wesselman, T.; Harbin, L.P.; Wolf, B.J.; Chung, D.; Hardiman, G. Genomics pipelines and data integration: Challenges and opportunities in the research setting. Expert Rev. Mol. Diagn. 2017, 17, 225-237. [CrossRef] [PubMed]

13. Benjamini, Y.; Hochberg, Y. Controlling the False Discovery Rate: A Practical and Powerful Approach to Multiple Testing. J. R. Stat. Soc. Ser. B (Methodol.) 1995, 57, 289-300. [CrossRef]

14. Draghici, S.; Khatri, P.; Tarca, A.L.; Amin, K.; Done, A.; Voichita, C.; Georgescu, C.; Romero, R. A systems biology approach for pathway level analysis. Genome Res. 2007, 17, 1537-1545. [CrossRef]

15. Garrett, S.M.; Baker Frost, D.; Feghali-Bostwick, C. The mighty fibroblast and its utility in scleroderma research. J. Scleroderma Relat. Disord. 2017, 2, 100-107. [CrossRef] [PubMed] 
16. Sargent, J.L.; Milano, A.; Bhattacharyya, S.; Varga, J.; Connolly, M.K.; Chang, H.Y.; Whitfield, M.L. A TGF $\beta$-Responsive Gene Signature Is Associated with a Subset of Diffuse Scleroderma with Increased Disease Severity. J. Investig. Dermatol. 2010, 130, 694-705. [CrossRef] [PubMed]

17. Milano, A.; Pendergrass, S.A.; Sargent, J.L.; George, L.K.; McCalmont, T.H.; Connolly, M.K.; Whitfield, M.L. Molecular Subsets in the Gene Expression Signatures of Scleroderma Skin. PLoS ONE 2008, 3, e2696. [CrossRef]

18. Yamaguchi, Y.; Takihara, T.; Chambers, R.A.; Veraldi, K.L.; Larregina, A.T.; Feghali-Bostwick, C.A. A peptide derived from endostatin ameliorates organ fibrosis. Sci. Transl. Med. 2012, 4, 136ra71. [CrossRef] [PubMed]

19. Yasuoka, H.; Larregina, A.T.; Yamaguchi, Y.; Feghali-Bostwick, C.A. Human skin culture as an ex vivo model for assessing the fibrotic effects of insulin-like growth factor binding proteins. Open Rheumatol. J. 2008, 2, 17-22.

20. Watanabe, T.; Nishimoto, T.; Mlakar, L.; Heywood, J.; Malaab, M.; Hoffman, S.; Feghali-Bostwick, C. Optimization of a murine and human tissue model to recapitulate dermal and pulmonary features of systemic sclerosis. PLoS ONE 2017, 12, e0179917. [CrossRef]

21. Kawanabe, Y.; Nauli, S.M. Endothelin. Cell. Mol. Life Sci. 2011, 68, 195-203. [CrossRef] [PubMed]

22. Leask, A.; Holmes, A.; Abraham, D.J. Connective tissue growth factor: A new and important player in the pathogenesis of fibrosis. Curr. Rheumatol. Rep. 2002, 4, 136-142. [CrossRef] [PubMed]

23. Bhattacharyya, S.; Wu, M.; Fang, F.; Tourtellotte, W.; Feghali-Bostwick, C.; Varga, J. Early growth response transcription factors: Key mediators of fibrosis and novel targets for anti-fibrotic therapy. Matrix Biol. 2011, 30, 235-242. [CrossRef]

24. Brigstock, D.R. Connective tissue growth factor (CCN2, CTGF) and organ fibrosis: Lessons from transgenic animals. J. Cell Commun. Signal. 2010, 4, 1-4. [CrossRef] [PubMed]

25. Bhattacharyya, S.; Chen, S.J.; Wu, M.; Warner-Blankenship, M.; Ning, H.; Lakos, G.; Mori, Y.; Chang, E.; Nihijima, C.; Takehara, K.; et al. Smad-independent transforming growth factor- $\beta$ regulation of early growth response-1 and sustained expression in fibrosis: Implications for scleroderma. Am. J. Pathol. 2008, 173, 1085-1099. [CrossRef]

26. Ibrahim, M.M.; Chen, L.; Bond, J.E.; Medina, M.A.; Ren, L.; Kokosis, G.; Selim, A.M.; Levinson, H. Myofibroblasts contribute to but are not necessary for wound contraction. Lab. Investig. 2015, 95, 1429-1438. [CrossRef] [PubMed]

27. Tomasek, J.J.; Haaksma, C.J.; Schwartz, R.J.; Howard, E.W. Whole animal knockout of smooth muscle $\alpha$-actin does not alter excisional wound healing or the fibroblast-to-myofibroblast transition. Wound Repair Regen. 2013, 21, 166-176. [CrossRef] [PubMed]

28. Conrad, P.A.; Giuliano, K.A.; Fisher, G.; Collins, K.; Matsudaira, P.T.; Taylor, D.L. Relative distribution of actin, myosin I, and myosin II during the wound healing response of fibroblasts. J. Cell Biol. 1993, 120, 1381-1391. [CrossRef] [PubMed]

29. Boor, P.; Ostendorf, T.; Floege, J. Renal fibrosis: Novel insights into mechanisms and therapeutic targets. Nat. Rev. Nephrol. 2010, 6, 643-656. [CrossRef]

30. Heinrich, P.C.; Behrmann, I.; Müller-Newen, G.; Schaper, F.; Graeve, L. Interleukin-6-type cytokine signalling through the gp130/Jak/STAT pathway. Biochem. J. 1998, 334 Pt 2, 297-314. [CrossRef]

31. Chung, C.D.; Liao, J.; Liu, B.; Rao, X.; Jay, P.; Berta, P.; Shuai, K. Specific inhibition of Stat3 signal transduction by PIAS3. Science 1997, 278, 1803-1805. [CrossRef] [PubMed]

32. Thiery, J.P.; Acloque, H.; Huang, R.Y.; Nieto, M.A. Epithelial-mesenchymal transitions in development and disease. Cell 2009, 139, 871-890. [CrossRef] [PubMed]

33. Kim, K.K.; Kugler, M.C.; Wolters, P.J.; Robillard, L.; Galvez, M.G.; Brumwell, A.N.; Sheppard, D.; Chapman, H.A. Alveolar epithelial cell mesenchymal transition develops in vivo during pulmonary fibrosis and is regulated by the extracellular matrix. Proc. Natl. Acad. Sci. USA 2006, 103, 13180-13185. [CrossRef] [PubMed]

34. Mistriotis, P.; Andreadis, T. Hair Follicle: A novel source of multipotent stem cells for tissue engineering and regenerative medicine. Tissue Eng. Part B Rev. 2013, 19, 265-278. [CrossRef] [PubMed]

(C) 2019 by the authors. Licensee MDPI, Basel, Switzerland. This article is an open access article distributed under the terms and conditions of the Creative Commons Attribution (CC BY) license (http:/ / creativecommons.org/licenses/by/4.0/). 